Motrivivência $\quad$ v. 28 , n. 48 , p. $61-75$, setembro/2016

\title{
APRECIAÇÃO DA BASE NACIONAL COMUM CURRICULAR E A EDUCAÇÃO FÍSICA EM FOCO
}

\author{
Laine Rocha Moreira' \\ Marcos Renan Freitas de Oliveira ${ }^{2}$ \\ Marta Genú Soares ${ }^{3}$ \\ Meriane Conceição Paiva Abreu 4 \\ Suziane Chaves Nogueira ${ }^{5}$
}

\begin{abstract}
RESUMO
O presente artigo analisa o manuscrito da Base Nacional Comum Curricular e compreende a concepção de Educação Física por ele proposta. Identifica a concepção atribuída à educação física pela Base Nacional Comum Curricular. Metodologicamente, utiliza a análise bibliográfica e documental, a dialética como método e aplica a análise de conteúdo, para tratar os dados. Constata que a Base Nacional Comum Curricular localiza a educação física na área da linguagem e a filia a um ecletismo no que diz respeito a sua concepção e corpo de conhecimento específico, gerando dada incoerência nos conteúdos e nos processos formativos deste campo de conhecimento. Conclui que o manuscrito, na fase de apresentação à comunidade, concretiza uma aliança entre educação e o capital, defendendo os interesses dos grupos hierárquicos centrais, transformando o direito à educação em serviço mercadológico.
\end{abstract}

Palavras-chave: Educação Básica; Educação Física; Currículo

1 Mestranda em Educação. Professora na Universidade do Estado do Pará (UEPA). Belém/Pará, Brasil.

E-mail: laine.educacaofisica@hotmail.com

2 Mestre em Educação. Coordenador Pedagógico da Secretaria Municipal de Educação de Bragança, Coordenador do Curso de Educação Física da Faculdade de Bragança (FABRA) e professor colaborador da Faculdade Pan Americana (FPA). Belém/Pará, Brasil. E-mail: marcosrenanef@yahoo.com

3 Pós-Doutora em Educação. Professora da Universidade do Estado do Pará (UEPA). Belém/Pará, Brasil.

E-mail: martagenu@gmail.com

4 Mestre em Educação. Professora de educação física, da educação básica, pela Secretaria do Estado de Educação (SEDUC) e pela Secretaria Municipal de Educação de Barcarena (SEMEC). Belém/Pará, Brasil.

E-mail: meri_black@hotmail.com

5 Mestranda em Educação. Universidade do Estado do Pará (UEPA). Belém/Pará, Brasil.

E-mail: suzianenogueira@gmail.com 


\section{INTRODUÇÃO}

O currículo está intimamente relacionado com o processo de formação humana, pois se constitui, ao longo do tempo, como um importante instrumento de conservação, transformação, renovação dos conhecimentos historicamente acumulados e produzidos pela humanidade, assim como, de socialização desses conhecimentos com o conjunto dos seres humanos, nas distintas sociedades, no decorrer da evolução humana.

Um currículo aponta diretivamente para uma concepção de homem e de sociedade, que se tem e que se pretende formar. Essas diferentes concepções influenciarão na seleção ou não de determinados tipos de conhecimento a serem ensinados e aprendidos na escola, do mesmo modo como os justificarão.

O currículo como parte da realidade complexa e contraditória da sociedade capitalista, está inserido em meio a interesses econômicos e políticos, sendo, portanto, palco de conflitos, onde estão em jogo os sentidos que distintos grupos sociais pretendem disputar e atribuir.

Nas últimas décadas do século $\mathrm{XX}$, a preocupação em torno das questões curriculares, no Brasil, vem ganhando espaço nas discussões das políticas educacionais nacionais, com vistas a atender as exigências concernentes aos organismos internacionais.
Notamos que as políticas curriculares advêm de forma hierárquica, não provocando e/ou permitindo realmente, a efetiva participação da comunidade escolar - reais conhecedores da complexidade da prática educacional.

Desde 1990, as ações do Ministério da Educação (MEC) passaram a incluir as políticas educacionais, tendo dentre suas competências, a educação básica, e sendo a Secretaria de Educação Básica (SEB), vinculada ao MEC, a responsável pela elaboração e implementação da política curricular para este segmento escolar, por meio de indicações curriculares norteadoras, como por exemplo, os Parâmetros Curriculares Nacionais (PCN).

A Lei de Diretrizes e Bases da Educação Nacional (LDBEN) 9394/96 determina que a União, Estados e Municípios devem estabelecer, de maneira conjunta, diretrizes norteadoras que busquem organizar currículos, assegurando-se uma base nacional comum. Atendendo a este princípio, o MEC Iançou em 2015 a Base Nacional Comum Curricular $(\mathrm{BNC})^{6}$ - uma outra proposta curricular, que tem como premissa $\mathrm{o}$ atendimento ao aspecto legal ${ }^{7}$, amparado pela Carta Magna, de 1988 (Art. 210), a qual determina que "serão fixados conteúdos mínimos para o ensino fundamental, de maneira a assegurar formação básica comum e respeito aos valores culturais e artísticos, nacionais e regionais" (BRASIL, 2012, p. 147) e pela Lei de Diretrizes e

6 A comissão do Ministério da Educação (MEC) tem utilizado a sigla BNC para se referir à Base Nacional Comum Curricular. Por isso, utilizaremos a sigla BNC, em conformidade com o MEC.

7 Cf. http://basenacionalcomum.mec.gov.br/\#/site/base/por-que

8 [...] "a ser complementada, em cada sistema de ensino e em cada estabelecimento escolar, por uma parte diversificada, exigida pelas características regionais e locais da sociedade, da cultura, da economia e dos educandos" (BRASIL, 1996, p. 01). 
Bases da Educação Nacional, cujo Art. 26 determina que "os currículos da educação infantil, do ensino fundamental e do ensino médio devem ter base nacional comum" ${ }^{\prime 8}$ [...] (BRASIL, 1996, p. 01).

Entretanto, a BNC convida a sociedade a analisar suas propostas formatadas anteriormente por um grupo de especialistas ou protagonistas ${ }^{9}$, indicados pelas secretarias estaduais de educação e selecionados a partir de determinados critérios, como por exemplo "ter participação anterior em políticas do MEC voltadas à educação básica" (BRASIL, 2015, p. 01).

Perante tal realidade, surgem algumas questões que advêm deste panorama, tais como: solicitar a sociedade a opinar, diante de um manuscrito que se encontra pronto; sem explicitar em que bases teórico-metodológicas fundamentam a BNC; ou ainda, que fundamentos epistêmicos, ontológicos e históricos estão no cerne da BNC.

Dadas as indefinições acima, a compreensão suscitada é a de que a BNC necessita de reflexão e discussão, tendo em vista que este manuscrito orientará os projetos político-pedagógicos das escolas do país, trazendo não apenas um currículo básico comum, mas uma proposta por áreas de conhecimento e seus elementos constituintes, além de um projeto que determina um tipo de ser humano, de educação e de sociedade.

Quanto à Educação Física, especificamente, como disciplina, a BNC menciona respectivamente os PCN de 1997, que correspondem ao ensino fundamental de $1^{\mathrm{a}}$ a $4^{\mathrm{a}}$ séries, os $\mathrm{PCN}$ de 1998 de $5^{\mathrm{a}}$ a $8^{\mathrm{a}}$ séries e os PCN de 2000 que abrangem o ensino médio, porém algumas concepções ainda não ficam claras no manuscrito. Por isso, o estudo problematiza: qual a concepção de Educação Física, bem como de ser humano, educação e sociedade são propostas pela BNC?

Para isto, o presente artigo tem como objetivo analisar a minuta disponibilizada pelo MEC, para o documento oficial da BNC, para compreender que concepção de Educação Física é por ele proposto, além dos projetos de sociedade, de educação e de ser humano.

Metodologicamente, o artigo está fundamentado no tipo de pesquisa bibliográfica e documental, opta pela dialética como método e, para tratamento dos dados se aplica a análise de conteúdo, inicialmente organizando o material, posteriormente o descrevendo analiticamente e, finalmente interpretando os dados (BARDIN, 2011).

Em atendimento ao objetivo proposto, o artigo está organizado da seguinte forma: inicialmente, com uma análise da minuta da BNC, disponibilizada no sítio do MEC e em fase de socialização com a comunidade - conceito, função, objetivos, justificativas, os agentes envolvidos, o projeto de sociedade, de educação e de ser humano; em seguida, apresenta e analisa o papel da Educação Física, a concepção, os elementos pensados e atribuídos pela BNC e, finalmente, traz os apontamentos e as conclusões correspondentes.

A relevância acadêmico-científica está na análise crítica da BNC, como manuscrito que pretende articular um currículo comum às diversas disciplinas e, mais especificamente à educação física, atribuindo-lhe 
uma concepção e uma maneira determinada de pensar a área, buscando compreender que projetos científico-epistemológicos são defendidos por esse manuscrito.

Quanto à relevância social, propõe-se pensar que projetos de ser humano, educação e sociedade são justificados pela Base Nacional Comum Curricular, discutindo-os analiticamente.

\section{Base Nacional Comum Curricular: um projeto à guisa de análise}

O debate acerca do estabelecimento de um currículo comum para a educação brasileira remonta da década de 80 , no entanto, intensifica-se a partir do estabelecimento da Lei de Diretrizes e Bases da Educação Brasileira, em 1996, das Diretrizes Curriculares Nacionais e dos Parâmetros Curriculares Nacionais e se materializa a partir da política, para atingir as metas do Plano Nacional de Educação (PNE) (MACEDO, 2014).

O manuscrito preliminar da BNC tem por objetivo definir, listar os conhecimentos fundamentais a serem ensinados nas redes de ensino básico assim como guiar os processos de avaliação e formação de professores. Essa construção se justifica na redução das desigualdades e garantia do direito à aprendizagem e ao desenvolvimento (BRASIL, 2015).

A implementação das bases se incorpora às medidas de adequação ao momento internacional de surgimento do modelo de um currículo nacional. Alves (2014, p. 1468) questiona a criação de uma "necessidade educacional" de imposição de um modelo curricular como gradualmente foi feito com o estabelecimento dos Parâmetros Curriculares Nacionais e, posteriormente na imposição de um sistema de avaliação de estudantes e escolas por meio de provas nacionais que culminam com as BNC.

Esse momento de internacionalização das políticas educacionais é citado por Alves (2014); Süssekind (2014); Macedo (2014); Cóssio (2014); Price (2014); Edling (2014) em um Dossiê Temático intitulado "Debates em torno da ideia de bases curriculares nacionais", publicado em 2014 na Revista Eletrônica e-Curriculum, do Programa de Pós-Graduação em Educação: Currículo da PUC-SP, como a causa do aumento do espaço dado aos modelos internacionais, apontando para um movimento crescente de incorporação de forças privadas no campo do currículo. Freitas (2012) já criticava esse movimento, apontando a ação dos "reformadores empresariais ${ }^{10 " ~ n a ~}$ educação pública.

Os reformadores empresariais ou grupos econômicos, denominação utilizada por Macedo (2014), argumentam pelo cumprimento às orientações dos organismos internacionais de priorizar políticas de alívio à pobreza e de redução da vulnerabilidade e desigualdades, com medidas compensatórias de implantação de modelos de países, como Estados Unidos, Austrália e Suécia para países latino-americanos, como é o caso do Brasil (PRICE, 2014); (EDLING, 2014); (FREITAS, 2012).

10 O termo é usado pelo autor com base em Ravitch (2011), que designa acordo entre políticos, mídia, empresários e empresas educacionais, institutos e fundações privadas e pesquisadores, alinhados à ideia de que o modo de organizar a iniciativa privada é o mais adequado para "consertar" a educação (FREITAS, 2012). 
Caberia então, para os reformadores empresariais, ao se estabelecer um currículo comum, a resolução dos problemas educacionais mais urgentes, como a redução do analfabetismo, por exemplo, assim como, a contribuição para a resolução de problemas sociais, como a redistribuição de renda, redução das desigualdades culturais e econômicas.

É esse romantismo que o discurso dos reformadores propaga, apresentando nexos com o ideário da educação como ferramenta de transformação social e o currículo como o caminho para atingi-la, conforme apontado por Süssekind (2014).

A autora demonstra pelo marco histórico do currículo, que a sua concepção como um produto/ processo técnico, que no caso da BNC aparece de forma contundente como uma tarefa política, na verdade camuflam os seus reais interesses.

Com, nem sempre declarados, interesses econômicos na solução para problemas da educação, veementemente descrito como a "crise da educação", defendem a necessidade de "currículo claro e objetivo" que nos deem caminhos para superar a "falta de preparo dos professores" e a "inadequação do material didático"; assim, alimentando uma dicotomia escola-sociedade calcada na ideia de "obsolescência da escola" e incompetência ou despreparo dos professores (SÜSSEKIND, 2014, p. 1515).

A padronização do currículo, dos conhecimentos a serem aprendidos na escola seria no discurso dos reformadores empresariais, uma arma social para extirpar com os problemas educacionais que há séculos compõem a pauta das políticas sociais, no entanto, essa não é a essência.
Entendemos que o currículo, como um dos elementos centrais do sistema de ensino, passa a ser uma imposição arbitrária dos grupos ou classes dominantes aos grupos ou classes dominados, ou seja, irá reproduzir as hierarquias dos conhecimentos, das classes de forma velada e não cumprirá o objetivo ideal.

A BNC deixa de ser considerada como um mero manuscrito técnico e passa a ser entendida em nossa análise, como uma política de formação de ser humano, que corresponde a um determinado modelo de educação e de sociedade.

Alves (2014) nessa direção aponta que não devemos reduzir o currículo/ processos a currículo/ objeto, mas identificar que tipo de ser humano esse currículo pretende formar. Por isso questiona: qual modelo de educação defende e que tipo de sociedade pretende alcançar? Baseamo-nos nas asserções de Freitas (2012) e Macedo (2014) para responder a esses questionamentos.

Em relação ao modelo educacional, a ênfase em gestão e adição de tecnologia são características do modelo empresarial transferido para o campo educacional, baseado no modelo neotecnicista de educação. Freitas (2012, p. 383) explica que esse antigo/ novo modelo:

Se apresenta, hoje, sob a forma de uma "teoria da responsabilização", meritocrática e gerencialista, onde se propõe a mesma racionalidade técnica de antes na forma de "standards", ou expectativas de aprendizagens medidas em testes padronizados, com ênfase nos processos de gerenciamento da força de trabalho da escola (controle pelo processo, bônus e punições), ancorada nas mesmas concepções oriundas da psicologia behaviorista, fortalecida pela econometria, ciências da informação 
e de sistemas, elevadas à condição de pilares da educação contemporânea.

A esse modelo de educação, Duarte (2001, p. 29) chama de "aprender a aprender", o qual:

Preconiza que à escola não caberia a tarefa de transmitir o saber objetivo, mas sim a de preparar os indivíduos para aprenderem aquilo que deles for exigido pelo processo de sua adaptação às alienadas e alienantes relações sociais que presidem o capitalismo contemporâneo. A essência do lema "aprender a aprender" é exatamente o esvaziamento do trabalho educativo escolar, transformando-o num processo sem conteúdo. Em última instância o lema "aprender a aprender" é a expressão, no terreno educacional, da crise cultural da sociedade atual.

O lema "aprender a aprender" expressa o afinamento do discurso educacional com o projeto neoliberal, considerado pelo autor como o projeto político de adequação das estruturas e instituições sociais às características do processo de reprodução do capital, no final do século XX (DUARTE, 2001). Um exemplo dessa caracterização é o protagonismo dos organismos privados nos debates sobre as bases comuns e a urgência em sua implementação.

Macedo (2014, p. 1539) destaca a participação do movimento "todos pela educação", liderado por empresas, como a Fundação Lemann, Fundação Itaú Social, entre outras, que acirra a interdependência entre Estado e mercado. Nela o "caráter público da educação, e sua ineficiência, funciona como exterior constitutivo que cria uma rede de demandas em torno de reformas marcadas pela lógica do mercado" (IBID).

Freitas (2012) chama de hipócrita esse discurso que prega ser possível estarmos "Todos pela educação", quando os interesses hegemônicos reduzem a educação à produção do trabalhador que está sendo esperado na porta das empresas e afirma que a proposta dos reformadores empresariais é dar legitimidade ao currículo básico, mínimo.

Esse currículo básico e mínimo pretende atingir as metas 2 - que pretende "Universalizar o ensino fundamental de nove anos para toda população de seis a quatorze anos" (BRASIL, 2010, p. 04) - e 3 - que busca "Universalizar, até 2016, o atendimento escolar para toda a população de quinze a dezessete anos e elevar, até 2020, a taxa líquida de matrículas no ensino médio para oitenta e cinco por cento, nesta faixa etária" (IBID, p. 05) do Plano Nacional de Educação, por meio de estratégias que definem os direitos de aprendizagem para a educação básica ${ }^{11}$.

O manuscrito da BNC objetiva sinalizar os percursos de conhecimento e desenvolvimento e assim garantir os direitos de aprendizagem por meio da definição dos objetivos de aprendizagem que fazem articulação entre as singularidades das áreas do conhecimento e de seus componentes e as especificidades dos estudantes ao longo da escolarização básica (BRASIL, 2015).

Macedo (2014, p. 1540) define os direitos de aprendizagem como as "expectativas dos alunos brasileiros por série ou

11 Cf. ainda, http://pne.mec.gov.br/pdf/pne_conhecendo_20_metas.pdf que trata sobre as vinte metas do Plano Nacional de Educação. 
por ciclo" e, portanto, diretamente relacionados à avaliação: "elaborar e adotar esses direitos, para que as redes, as escolas e os professores saibam a que objetivos pedagógicos precisam responder" (IBID).

Sobre a justificativa da proposta de um currículo nacional, Cóssio (2014) afirma que ela está amparada, de acordo com seus defensores, na redução das desigualdades regionais, garantindo os direitos às aprendizagens. Há a argumentação de que quanto maior é a vulnerabilidade em que estão inseridos os alunos, menor é a sua aprendizagem.

A autora ainda afirma, que as aprendizagens que são entendidas como direito de todos, com vistas a reduzir as desigualdades são aquelas obrigatórias e, que em nome da proclamação do currículo como direito de todos, justifica-se essa obrigação. Dessa forma, todos têm de aprender, sob pena de reprovação, recuperação ou expulsão.

Essa relação é defendida por Frei$\operatorname{tas}^{12}$ (2012) ao apresentar o caso norte- americano de implantação das bases nacionais para a educação. O autor afirma que existe uma relação de identidade entre qualidade da educação e "nota alta" e que a lição desse país, demonstra que o foco deve ser sempre em melhorar a educação e não simplesmente aumentar as pontuações nas provas de avaliação.

As consequências desse processo são apresentadas por Duarte (2001), como a expropriação da escola de sua tarefa social: a transmissão do saber objetivo, cientificamente organizado e sistematizado, na diluição do papel da escola em transmitir esse saber, na descaracterização do papel do professor, na própria negação do ato de ensinar. Há também o processo de "demonização dos professores"13, em virtude do fracasso dos alunos nas avaliações padronizadas; competição entre profissionais e escolas; pressão sobre o desempenho dos alunos e preparação para os testes, fraudes, aumento da segregação socioeconômica no território, aumento da segregação socioeconômica dentro da escola, precarização da formação do professor ${ }^{14}$.

Para finalizar essa análise, corroboramos com a apreciação feita pelo professor Doutor Luiz Carlos de Freitas divulgada recentemente em seu blog de opinião ${ }^{15}$ :

A educação, como processo formativo, está sendo reduzida a aprendizagem nas teses dos reformadores empresariais. Não sabendo como lidar com a educação (uma relação ampla entre educandos e educadores) eles a reduziram a aprendizagem (um resultado do aluno, medido pelo seu desempenho em testes de habilidades e competências). Com esta redução, a noção de qualidade fica igualmente reduzida à pontuação que o aluno obtém. Toda a complexidade e riqueza da ação educativa desaparece e com isso, as soluções mágicas e as receitas, tomam lugar da boa educação.

Acreditamos que a aprendizagem depende de um processo formativo, guiado

12 O autor também apresenta sua opinião sobre a BNC por meio de diversos textos em seu blog: http:// avaliacaoeducacional.com/.

13 Esse processo é apontado por Süssekind (2014) como a desmoralização e des-credibilização dos professores.

14 Essas consequências são apontadas por Freitas (2012, p. 389). Na caracterização da atuação dos reformadores educacionais, o autor afirma que a implementação de políticas, como a BNC não compõem apenas uma "reforma educacional", mas uma "reforma fiscal" da educação. 
pelo currículo e por isso, não pode ser medida em testes de múltipla escolha. Nas palavras de Vygotsky (1998, p. 115) "uma correta organização da aprendizagem da criança conduz ao desenvolvimento" das capacidades humanas ou o salto qualitativo na percepção da realidade. Por isso, entendemos ser essa a função de uma base comum que esteja comprometido com a formação humana das crianças e jovens.

\section{A Educação Física em Foco: com a palavra a Base Nacional Comum Curricular}

A definição dos "direitos e objetivos de aprendizagem" é o objetivo central da elaboração do documento regulatório, relacionada às quatro áreas do conhecimento - ciências da natureza, ciências humanas, linguagens e matemática e seus respectivos componentes curriculares para todas as etapas da educação básica - , sendo que o ponto de partida para a definição dos objetivos de aprendizagem são os direitos de aprendizagem, isto é, um conjunto de proposições que orientam as escolhas feitas pelos componentes curriculares na definição dos seus objetivos de aprendizagem.

Quanto à área de linguagens, que reúne quatro componentes curriculares: língua portuguesa, língua estrangeira moderna, arte e educação física, observarmos, por exemplo, que os objetivos gerais da área de linguagens para a educação básica, centralizam-se na língua portuguesa, especificamente na leitura e escrita, enquanto que os demais campos de conhecimento sugerem uma interpretação de acessório ou meio para que aqueles sejam desenvolvidos.

A Educação Física como área de estudo multidisciplinar e intervenção pedagógica na educação básica, que tem como objeto de estudo as práticas corporais e que na educação crítico superadora é adotada como cultura corporal, não é apenas uma linguagem corporal, mas um campo de conhecimento específico e por isso, precisa ser contemplado em suas particularidades.

Compreender a cultura corporal, tradutora das práticas corporais como objeto de estudo da educação física implica reconhecer a atividade prática do homem, o trabalho, as relações objetivas materiais reais dos homens com a natureza e com os outros homens, para o centro do sistema explicativo. Essa perspectiva é explicada da seguinte forma por Micheli Escobar:

\begin{abstract}
A "cultura corporal" é uma parte do homem. É configurada por um acervo de conhecimento, socialmente construído e historicamente determinado, a partir de atividades que materializam as relações múltiplas entre experiências ideológicas, políticas, filosóficas e sociais e os sentidos lúdicos, estéticos, artísticos, agonistas, competitivos ou outros, relacionados à realidade, às necessidades $\mathrm{e}$ as motivações do homem. O singular dessas atividades - sejam criativas ou imitativas - é que o seu produto não é material nem é separável do ato de sua produção; por esse motivo o homem Ihe atribui um valor de uso particular. Dito de outra forma, as valoriza como atividade, em si mesma. Essas atividades são realizadas seguindo modelos socialmente elaborados, portadores de significados ideais atribuídos socialmente (ESCOBAR, 2009, p. 127-128).
\end{abstract}

Das atividades corporais historicamente criadas e socialmente desenvolvidas, em torno da relação entre múltiplas experiências e interesses subjetivos do ser humano, torna-se visível hoje, um acúmulo de conhecimentos sistematizados sobre 
ginásticas, lutas, danças, jogos, capoeira, esporte, exercício físico sistematizado, dentre outros, que se constituem o objeto de estudo do professor de educação física na escola e nos diversos espaços formativos.

Compreendemos que a centralidade dos objetivos gerais da área da linguagem no componente curricular língua portuguesa implicará no estreitamento curricular - redução de carga horária - da Educação Física, da arte e da língua estrangeira moderna. Tal estreitamento curricular deve se materializar em virtude das avaliações nacionais oficiais, como Provinha Brasil e Avaliação Nacional de Aprendizagem (ANA), centralizando-se apenas em dois componentes curriculares - língua portuguesa e matemática.

Portanto, reivindicamos a educação física como "[...] um campo de conhecimento que se estrutura a partir das práticas históricas, socialmente produzidas, cientificamente estudadas e investigadas e, criativamente, ensinadas de geração a geração, referentes à cultura corporal" (TAFFAREL; Et al., 2006, p. 161).

A necessidade histórica de garantir acesso à especificidade da educação física é fulcral, porque a assimilação do conhecimento da cultura corporal contribui para nos tornarmos humanos, visto que este envolve um complexo de ação, que permite elevar o padrão cultural e esportivo dos indivíduos, mediante o desenvolvimento da capacidade humana de entender, explicar, agir no enfretamento da realidade concreta.

Na educação infantil, o manuscrito da BNC propõe a organização curricular por cinco campos de experiências - o eu, o outro e o nós; corpo, gestos e movimentos; escuta, fala, pensamento e imaginação; traço, sons, cores e imagens; espaços, tempos, quantidades, relações e transformações. Apesar de organizar por campos de experiências, dentre eles "corpo, gestos e movimentos", o manuscrito não explica como o componente curricular educação física se articula de tal forma, quanto à organização do trabalho pedagógico. Diante disso, propormos a clareza quanto à inserção do componente curricular educação física, na educação infantil, mediante à organização curricular, por campos de experiências.

O manuscrito também afirma que os anos iniciais do ensino fundamental serão materializados pela unidocência e os anos finais do ensino serão efetivados pela pluridocênia. Tal afirmação reduz a intervenção do professor de educação física apenas aos anos finais do ensino fundamental e ensino médio, tendo em vista que apenas um professor vai ministrar todos os componentes curriculares nos anos iniciais do ensino fundamental. Propomos ainda clareza e a afirmação quanto à obrigatoriedade do componente curricular educação física na educação básica.

O manuscrito define ainda, a cultura corporal de movimento como objeto de estudo da educação física, entendida como as práticas corporais - brincadeiras e jogos, esportes, exercícios físicos, ginásticas, lutas, práticas corporais alternativas, práticas corporais de aventura, praticas corporais rítmicas. As práticas corporais como objeto de estudo da educação física são compreendidas:

[...] como uma forma de relação do ser humano com o mundo e de interação com outros sujeitos, que, ao possibilitarem a construção de sentidos e significados singulares, configuram-se como produções diversificadas de cultura. Suas diferentes manifestações 
assumem, no mundo contemporâneo, uma importância cada vez maior no cotidiano das pessoas e na história social, constituindo subjetividades e identidades, quer seja na dimensão do lazer, quer seja na dimensão da saúde. (BRASIL, 2015, p. 96).

Portanto, definem as práticas corporais como abstrações, sem nexo com a realidade concreta e reduzindo sua concepção ao lazer e à saúde, que também são tratados no manuscrito como idealizados, desconsiderando a concretude da existência humana, tendo em vista que na sociedade capitalista, o lazer e a saúde são tratados como mercadorias, que estão acessíveis a poucos, ou seja, àqueles que concentram a riqueza e dela podem usufruir, comprando este lazer e saúde, diferentemente da maioria da população, alijada dos direitos anunciados na Carta Magna.

Quanto à definição da cultura corporal de movimento como objeto de estudo da educação física, nossa postura é de problematização dessa compreensão, em função de que "não houve, não há e não pode haver matéria sem movimento, nem movimento sem matéria" (CHEPTULIN, 1982, p. 162). Portanto, torna-se redundante falar em cultura corporal de movimento, pois o movimento é inerente à matéria $\mathrm{e}$, nesse movimento há transformações. Este objeto de estudo desconsidera, portanto, a historicidade, a dialética, a realidade material e a produção humana, ratificando, ao contrário, o idealismo.

O manuscrito enfatiza os objetivos específicos do componente curricular educação física, tendo a prática corporal como linguagem e organizados em cinco ciclos de escolaridade. Dois ciclos nos anos iniciais do ensino fundamental $\left(1^{\circ}, 2^{\circ}\right.$ e $3^{\circ}$ anos; $4^{\circ}$ e $5^{\circ}$ anos), dois ciclos nos anos finais do ensino fundamental $\left(6^{\circ}\right.$ e $7^{\circ} ; 8^{\circ}$ e $9^{\circ}$ anos), e por fim, um ciclo do ensino médio $\left(1^{\circ}\right.$, $2^{\circ}$, e $3^{\circ}$ anos).

Os objetivos estão organizados por ciclos, porém com a continuação das séries, apenas trocados pela terminação "ano". Os ciclos devem ter objetivos diferentes e isso é observado no manuscrito, porém não mostra claramente a diferença de objetivos por ano, além de os conteúdos serem os mesmos. Dessa forma, os critérios de progressão dos conteúdos estão frágeis e sem relação com a socialização do conhecimento científico, nas suas formas mais desenvolvidas, conforme se define:

[...] características dos sujeitos e contexto de atuação, sinalizando tendências de organização do conhecimento que vão, das esferas sociais mais familiares às menos familiares, das temáticas mais frequentes às menos frequentes, das práticas corporais mais corriqueiras as menos comuns, de reflexão mais localizada a mais universal (BRASIL, 2015, p. 97).

A inconsistência dos critérios de progressão e conteúdos no decorrer dos anos e dos ciclos abre a possibilidade de o professor trabalhar os mesmos objetivos e conteúdos no ciclo todo. Também, não fica claro como se dá a articulação proposta pelo manuscrito dos objetivos de aprendizagem com as oito dimensões do conhecimento apresentadas: "experimentação e produção, fruição, reflexão sobre ação, construção de valores, analise e compreensão crítica das praticas corporais e protagonismo comunitário" (BRASIL, 2015, p. 98).

O manuscrito da forma que está apresentado suscita uma confusão entre 
esporte e jogo, pois o mesmo possibilita a interpretação de que jogos e esportes são similares, em suas concepções e objetivos de aprendizagem. Jogos e esportes apresentam particularidades, embora inclusos na cultura corporal.

Outra problemática, diz respeito ao conteúdo ginástica, que vem vinculada à ginástica geral, permitindo interpretar que a ginástica geral é a ginástica. É importante esclarecer que a ginástica geral é uma modalidade da ginástica e, portanto, não a conceitua em sua totalidade.

No manuscrito ainda, interpretam-se as práticas corporais rítmicas sustentadas em atividades não sistematizadas e pertencentes ao cotidiano das comunidades, mais especificamente, nas danças folclóricas, étnicas. Além de apregoar que as diversas comunidades não organizam suas manifestações corporais rítmicas, ainda desconsidera a competência da organização do professor quanto à ação profissional docente sobre o conteúdo.

A dança está inclusa no manuscrito, no componente curricular artes, porém é um conteúdo vinculado à educação física, segundo o Coletivo de Autores (2012), pois é um conhecimento da cultura corporal.

Ademais, no manuscrito restringem essa prática corporal dança ao lazer. Neste viés, propomos a dança como elemento da cultura corporal, que traduz as práticas corporais como objeto de estudo da educação física, pois ela tem "seus fundamentos na própria vida, concretizando-se numa expressão dela e não numa produção acrobática" (COLETIVO DE AUTORES, 2012, p. 81).

Não há a dispensa da técnica, mas deve vir articulada ao pensamento e a descoberta, para que o aluno compreenda o significado da dança e sua expressão, ou seja, há valorização da técnica e do conteúdo expressivo contido na dança, sendo que a técnica está em paralelo à disponibilidade corporal, às várias formas de apreender a realidade e não deve ser o trabalho inicial do professor (COLETIVO DE AUTORES, 2012). Assim, a educação física não vai se preocupar somente com a técnica, mas também com ela, entendendo-a como um processo reflexivo sobre essa mesma técnica.

As técnicas devem ser compreendidas como instrumentos necessários de um jogo, de uma série de ginástica, de passos de uma dança etc. Contudo, afirmar a necessidade do domínio das técnicas de execução dos fundamentos das diferentes modalidades esportivas não significa polarizar nosso pensamento em direção ao rigor técnico do esporte de alto rendimento (COLETIVO DE AUTORES, 2012, p. 84).

A dança é processo, é criação e recriação, oriunda da atividade dos seres humanos entre si e de sua relação com a natureza, possuindo um significado que ultrapassa a técnica de alto rendimento.

[...] uma dança é uma forma de existência humana, a qual não pode ser aprisionada nos limites de uma descrição, demonstração ou apresentação apesar da constância 'aparente' da sua forma -, pois se reconstrói a cada existencialização/ execução nos corpos dos dançarinos e das dançarinas (GEHRES In GONZÁLEZ; FENSTERSEIFER, 2014, p. 186).

A dança, portanto, não é só para o lazer, entendido, no manuscrito da BNC, como algo sem fundamentação teórica, 
desprovida, portanto de discussão. Além disso, o manuscrito coloca um estilo de dança, que é a dança de salão misturado com a modalidade de dança, que é a dança de rua e, com as classificações, como quanto à origem das danças, que são as danças étnicas e, ainda, com fins de lazer, dados os verbos apreciar, desfrutar.

Sobre o exercício físico, entendemos que este não deve ser reduzido a programas de treinamento, pois a sua realização não é apenas para manter a saúde, visto que estas atividades ampliarão e desenvolverão a capacidade humana, no sentido de enriquecer a vida, pois, na medida em que o sujeito está se apropriando da cultura corporal elaborada por gerações passadas, está assimilando uma síntese dessa experiência, apreendendo os seus meios de produção. Portanto, na proporção que a atividade corporal ganha um sentido particular para o sujeito, ela amplia seu significado histórico e social. $\mathrm{O}$ exercício físico, então deve ser entendido como unido aos componentes da cultura corporal e não isolado em programas de treinamento, como apregoa o manuscrito.

A BNC precisa esclarecer que a educação física se apropriou das práticas corporais humanas e as desenvolveu, dando-lhes um trato ontológico, epistemológico e pedagógico para torná-lo conhecimento científico e de ensino.

Portanto, a cultura corporal foi construída historicamente e se consolidou como conhecimento salutar aos seres humanos, contribuindo para aguçar a criatividade e a imaginação, por meio da elaboração e a elevação do pensamento teórico. Sem essa compreensão, não vamos abranger os limites, contradições e possibilidades que estão colocadas para o ensino da cultural corporal na educação física à educação básica.

\section{CONSIDERAÇÕES FINAIS}

As reflexões teóricas realizadas neste artigo, possibilitam-nos concluir que o processo que desencadeou a elaboração do manuscrito das BNC foi mediado pelos interesses dos reformadores empresariais, que estabelecem aliança com o poder público, com implicações para as políticas oficiais, para garantir ações pedagógicas da educação básica, a concepção de sociedade, de ser humano e de educação, orientadas pela e para a mercantilização da vida. Para tanto, a burguesia dita, por meio dos organismos internacionais, as orientações para as políticas educacionais em escala global, sintetizando seus interesses imediatos e históricos.

O manuscrito preliminar da BNC aparentemente explicita a preocupação com a precariedade da escola pública, com a defesa contundente dos diretos e objetivos de aprendizagem de todos os sujeitos que estão na escola pública brasileira, porém o fato de não mencionar sob quais condições objetivas e subjetivas serão necessárias para garantir a materialização desses direitos e objetivos, demonstra, neste silêncio, que o objetivo central da BNC é responsabilizar a escola, os professores e os alunos diante de seu suposto fracasso. Contraditoriamente, o fracasso da escola pública é a força motriz para efetivação de políticas educacionais de meritocracia e privatização neste campo.

Para medir o nível do fracasso da escola, o mecanismo imediato se dá pela avaliação educacional e é neste quesito que a BNC tem sua legitimidade garantida para os reformadores empresariais, tendo em vista sua obsessão pela uniformização/ padronização e, posteriormente, avaliação da aprendizagem — dados que justificam a 
incapacidade do Governo Brasileiro em gerir a educação pública, tendo como receita a privatização.

As contradições do movimento mais geral que sustentam a elaboração e implementação da BNC refletem no componente curricular da educação física de forma imediata na localização desta, na área das linguagens, tendo sua importância rebaixada quando os objetivos gerais desta área do conhecimento estão voltados majoritariamente para a língua portuguesa, que junto com matemática, são os únicos componentes curriculares "existentes" nas avaliações educacionais.

O manuscrito preliminar das BNC apresenta um ecletismo no que diz respeito à concepção de educação física, isto é, não demonstra clareza quanto à defesa histórica deste componente curricular na educação básica e nem se alinha à reivindicação desta como um campo de conhecimento multidisciplinar e de intervenção pedagógica, que tem como objeto de estudo as práticas corporais, adotadas como cultura corporal, na educação crítico superadora, historicamente construída pela humanidade.

Diante de tal ecletismo, o manuscrito não consegue apresentar uma coerência interna e lógica, no que diz respeito aos conteúdos de ensino da educação física e não dá conta de explicitar a ampliação das possibilidades formativas dos conhecimentos da educação física durante anos, que compõem a educação básica e os ciclos de aprendizagem.

Dessa forma, propomos uma inversão na lógica hierárquica na elaboração do manuscrito, ou seja, que este seja construído e debatido pela comunidade escolar e acadêmico-científica, por meio de fóruns, reuniões, congressos, antes de sua promulgação e aplicação, favorecendo a sistematização de um documento norteador das ações pedagógicas da/ na escola, alinhadas aos interesses da classe trabalhadora, no que diz respeito, ao processo de apropriação do conhecimento sistematizado na educação básica - levando em consideração que já existem currículos sendo desenvolvidos nas escolas brasileiras, frutos da própria realidade a qual estão inseridos (reflexão da comunidade escolar) -, para além de uma exigência lógico-formal, com características mediadas pelos interesses dos formadores empresariais, isto é, do capital.

\section{REFERÊNCIAS}

ALVES, Nilda. Sobre a possibilidade e a necessidade curricular de uma base nacional comum. Revista e-Curriculum, São Paulo, v. 12, n. 03 p. 1464 - 1479 out./ dez. 2014.

BARDIN, Laurence. Análise de conteúdo.

Tradução Luís Antero Reto; Augusto Pinheiro. São Paulo: Edições 70, 2011.

BRASIL. Base Nacional Comum

Curricular. Disponível em http:// basenacionalcomum.mec.gov.br/. Acesso em 25 de novembro de 2015.

\section{BRASIL. Constituição da República}

Federativa do Brasil: promulgada em 5 de outubro de 1998. Obra coletiva de autoria da Editora Saraiva com a colaboração de Luiz Roberto Curia, Lívia Céspedes e Juliana Nicoletti. 47. ed. atual. e ampl. São Paulo: Saraiva, 2012. (Coleção Saraiva de legislação).

BRASIL. Lei de Diretrizes e Bases da Educação Nacional 9394/96. Disponível em: http://www.planalto. gov.br/ccivil_03/Leis/L9394.htm Acesso em janeiro de 2015. 
BRASIL. Planejando a próxima década: conhecendo as 20 metas do PNE. Disponível em http://pne.mec.gov.br/ pdf/pne_conhecendo_20_metas.pdf Acesso em 25 de novembro de 2015.

BRASIL. Plano Nacional de Educação decênio 2011-2020. Brasília, Ministério da Educação (MEC), 2010.

CHEPTULIN, Alexandre. A dialética materialista: categorias e leis da dialética. São Paulo: Alfa-Ômega, 1982.

CÓSSIO, Maria de Fátima. Base Comum Nacional: uma discussão para além do currículo. Revista e-Curriculum, São Paulo, v. 12, n. 03 p. 1570 - 1590 out./ dez. 2014.

COLETIVO DE AUTORES. Metodologia do Ensino de Educação Física. 2. ed. rev. São Paulo: Cortez, 2012.

DUARTE, Newton. Vigotski e o "aprender a aprender": crítica às apropriações neoliberais e pós- modernas da teoria Vigotskiana. 2. ed. Campinas: Autores Associados, 2001.

EDLING, Silvia. O conceito de pluralidade no currículo nacional sueco: estudando a importância de livros didáticos teóricos de formação de professores para interpretar e constatar as diferentes facetas de violência no trabalho diário de professores. Revista e-Curriculum, São Paulo, v. 12, n. 03 p. 1530 - 1555 out./ dez. 2014.

ESCOBAR, Micheli Ortega. Coletivo de Autores: a cultura corporal em questão. In: COLETIVO DE AUTORES. (Posfácio). Metodologia do ensino de educação Física. 2. ed. rev. São Paulo: Cortez, 2009.

FREITAS, Luiz Carlos de. Os reformadores Empresariais da Educação: da desmoralização do magistério à destruição do sistema público de educação. Revista Educação e Sociedade, Campinas, v. 33, n. 119, p. 379-404, abr./ jun. 2012.

GEHRES, Adriana de Faria. Dança. In: GONZÁLEZ, Fernando Jaime; FENSTERSEIFER, Paulo Evaldo (org.). Dicionário crítico de educação física. 3. ed. rev. e ampl. ljuí: Ed. Unijuí, 2014. $680 \mathrm{p}$.

MACEDO, Elizabeth. Base Nacional Curricular Comum: novas formas de sociabilidade produzindo sentidos para educação. Revista e-Curriculum, São Paulo, v. 12, n. 03 p. 1530 - 1555 out./ dez. 2014.

PRADO, Iara Glória Areias. O MEC e a reorganização curricular. Disponível em: http://www.scielo. br/scielo.php?script =sci_arttext \&pid =S0102-88392000000100011 Acesso em janeiro de 2015.

PRICE, Todd Alan. Comum pra quem? Revista e-Curriculum, São Paulo, v. 12, n. 03. p. 1614 - 1633 out./ dez. 2014.

SÜSSEKIND, Maria Luiza. As (im) possibilidades de uma base comum nacional. Revista e-Curriculum, São Paulo, v. 12, n. 03 p. 1512 - 1529 out./ dez. 2014.

TAFFAREL, Celi Nelza Zulke. Et al. Formação de professores de educação física para a cidade e o campo. Pensar a Prática, Goiânia, v. 9, n. 2, p. 153-179, 2006.

VYGOTSKY, Liev Semiónovich. Aprendizagem e desenvolvimento intelectual na idade escolar. In: VYGOTSKY, Liev Seminiónovich; LURIA, Alexander Romanovich; LEONTIEV, Alexei Nikolaievich. Linguagem, desenvolvimento e aprendizagem. São Paulo: Ícone, Editora da Universidade de São Paulo, 1998, p. 103-117. 
V. $28, \mathrm{n}^{\circ} 48$, setembro/2016

\title{
ANALYSIS OF THE NATIONAL COMMON CURRICULUM BASIS AND PHYSICAL EDUCATION IN FOCUS
}

\begin{abstract}
This article analyzes the manuscript of the National Common Curriculum Basis and it comprehends the conception of Physical Education. It identifies the concept attributed to physical education by the National Common Curriculum Basis. Methodologically, it uses a bibliographic and documentary analysis (National Common Curriculum Basis), the dialectic as method and applying content analysis to process data. It verifies that the National Common Curriculum Basis identifies the physical education in the language field and it affiliates to an eclecticism regarding to their conception and specific body of knowledge, generating inconsistency in content and the formative processes of this knowledge field. It concludes that the manuscript materializes an alliance between education and capital, defending the central hierarchical groups' interests, transforming the right to education in marketing service.
\end{abstract}

Keywords: Basic Education; Physical Education; Curriculum

\section{APRECIACIÓN DE LA BASE NACIONAL COMÚN CURRICULAR Y LA EDUCACIÓN FÍSICA EN EL FOCO}

\section{RESUMEN}

El presente artículo analiza el manuscrito de la Base Nacional Común Curricular y entiende la concepción de la Educación Física propuso. Identifica la concepción atribuido a la Educación Física de Base Nacional Común Curricular. Metodológicamente, utiliza revisión de la biografia y el documento (Base Nacional Común Curricular), la dialéctica como método y aplica el análisis de contenido, para procesar los datos. Señala que la Base Nacional Común Curricular localiza la Educación Física en el área del lenguaje y filia a un eclecticismo en cuanto a su concepción y cuerpo del conocimiento especifico, generando dada incoherencia en el contenido y procesos en la formación de este campo del conocimiento. La conclusión de que el manuscrito concretado una alianza entre educación y el capital. La defensa de los intereses del grupos jerárquicos, el centro de torneado el derecho a la educación en el servicio mercadeo.

Palabras-clave: Educación básica; Educación Física; Currículun

Recebido em: abril/2016

Aprovado em: agosto/2016 